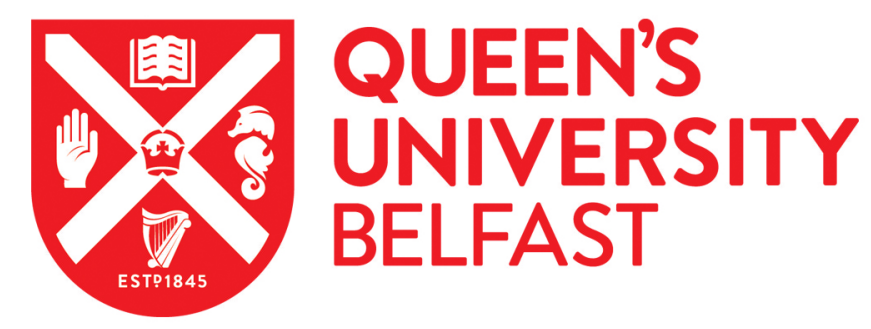

\title{
Recognizing Symptom Burden in Advanced Prostate Cancer A Global Patient and Caregiver Survey
}

Drudge-Coates, L., Oh, W. K., Tombal, B., Delacruz, A., Tomlinson, B., Ripley, A. V., Mastris, K., O'Sullivan, J. M., \& Shore, N. D. (2017). Recognizing Symptom Burden in Advanced Prostate Cancer A Global Patient and Caregiver Survey. Clinical genitourinary cancer, 1-9. https://doi.org/10.1016/j.clgc.2017.09.015

Published in:

Clinical genitourinary cancer

Document Version:

Version created as part of publication process; publisher's layout; not normally made publicly available

Queen's University Belfast - Research Portal:

Link to publication record in Queen's University Belfast Research Portal

\section{Publisher rights}

Copyright 2017 the authors.

This is an open access article published under a Creative Commons Attribution-NonCommercial-NoDerivs License

(https://creativecommons.org/licenses/by-nc-nd/4.0/), which permits distribution and reproduction for non-commercial purposes, provided the author and source are cited.

\section{General rights}

Copyright for the publications made accessible via the Queen's University Belfast Research Portal is retained by the author(s) and / or other copyright owners and it is a condition of accessing these publications that users recognise and abide by the legal requirements associated with these rights.

Take down policy

The Research Portal is Queen's institutional repository that provides access to Queen's research output. Every effort has been made to ensure that content in the Research Portal does not infringe any person's rights, or applicable UK laws. If you discover content in the Research Portal that you believe breaches copyright or violates any law, please contact openaccess@qub.ac.uk. 


\title{
Recognizing Symptom Burden in Advanced Prostate Cancer: A Global Patient and Caregiver Survey
}

\author{
Lawrence Drudge-Coates, ${ }^{1}$ William K. Oh, ${ }^{2}$ Bertrand Tombal, ${ }^{3}$ Anthony Delacruz, ${ }^{4}$ \\ Brian Tomlinson, ${ }^{5}$ Aimee Vella Ripley, ${ }^{6}$ Ken Mastris, ${ }^{7}$ Joe M. O’Sullivan, ${ }^{8}$ \\ Neal D. Shore ${ }^{9}$
}

\section{Abstract}

An international survey was conducted in 927 men with advanced prostate cancer (aPC) and 400 caregivers to assess symptom communication. Patients with aPC often ignore pain and pain-related symptoms, do not discuss pain with their physician, and have difficulty discussing symptoms. Effective communication among patients, caregivers, and health care providers may improve symptom and disease management and patient quality of life.

Background: Bone metastases in men with prostate cancer are often initially asymptomatic, resulting in delayed identification, diagnosis, and appropriate treatment.To assess how patients with advanced prostate cancer (aPC) communicate symptoms to health care providers, an international patient survey was conducted. Methods: An online and phone survey was conducted by Harris Poll in 11 countries (Brazil, France, Germany, Japan, Italy, Netherlands, Singapore, Spain, Taiwan, United Kingdom, United States) from February 12 to October 27, 2015, in men with aPC (ie, those who reported as having PC beyond the prostate [metastatic]) and their caregivers.Cell weighting was used to ensure equal weight of data across countries. Percentages are based on weighted $\mathrm{n}$ values. Results: $\mathrm{A}$ total of 927 men with $\mathrm{aPC}$ (weighted $\mathrm{n}=664$ ) and 400 caregivers completed the survey. Most commonly reported symptoms were fatigue $(73 \%)$, urinary symptoms $(63 \%)$, sexual function symptoms $(62 \%)$, and bone pain $(52 \%)$. Of 568 patients with bone metastases (weighted $n=421$ ), most $(73 \%)$ noticed pain before receiving a diagnosis of metastatic PC. Most patients with aPC (56\%) were uncertain if their pain was cancer related, $55 \%$ felt they had to live with daily pain, $45 \%$ sometimes ignored pain, and $39 \%$ had difficulty talking about pain. Patients who had a caregiver were more likely than those without to discuss pain at every visit $(45 \%$ vs. $32 \%, P<.05)$. Conclusions: Disease symptoms in aPC are often underrecognized. Tools encouraging effective communication among patients, caregivers, and health care providers on early symptom reporting may lead to enhanced symptom and disease management.

Clinical Genitourinary Cancer, Vol. m, No. m, m- @ 2017 The Author(s). Published by Elsevier Inc. This is an open access article under the CC BY-NC-ND license (http://creativecommons.org/licenses/by-nc-nd/4.0/).

Keywords: Bone pain, Communication, International, Metastatic prostate cancer, Pain

\section{Introduction}

Prostate cancer (PC) is the second most common malignancy in men worldwide, with an estimated 1.1 million men across the world diagnosed in 2012, and the fifth leading cause of cancer-related

${ }^{1}$ King's College Hospital NHS Foundation Trust, London, UK

${ }^{2}$ Tisch Cancer Institute-Icahn School of Medicine at Mount Sinai, New York, NY

${ }^{3}$ Institut de Recherche Clinique, Université Catholique de Louvain, Louvain-la-Neuve,

Belgium

${ }^{4}$ Memorial Sloan-Kettering Cancer Center, New York, NY

${ }^{5}$ CancerCare, New York, NY

${ }^{6}$ Harris Poll, New York, NY

${ }^{7}$ Europa Uomo, The European Prostate Cancer Coalition, Essex, UK death in men, with 307,000 deaths reported worldwide in 2012 . $\mathrm{PC}$ is an androgen-dependent disease that initially responds to androgen-deprivation therapy (ie, chemical or surgical castration). However, most men will become resistant to androgen-deprivation

\footnotetext{
${ }^{8}$ Queen's University School of Medicine, Belfast, UK

${ }^{9}$ Carolina Urologic Research Center, Myrtle Beach, SC

Submitted: Jul 10, 2017; Revised: Sep 21, 2017; Accepted: Sep 24, 2017

Address for correspondence: Lawrence Drudge-Coates, MSc, Urological Oncology

Clinical Nurse Specialist and Honorary Lecturer, King's College Hospital NHS

Foundation Trust, Denmark Hill, London, UK SE5 9RS

E-mail contact: Idrudge-coates@nhs.net
} 


\section{Advanced Prostate Cancer Global Survey}

therapy over time, developing nonmetastatic castration-resistant PC (CRPC), in which a rise in prostate-specific antigen is often the first detectable sign. ${ }^{2-4}$ For some men, nonmetastatic CRPC will progress to metastatic CRPC, which is still uniformly incurable, although several new treatment options have been shown to significantly improve survival, including traditional taxane chemotherapy (docetaxel), new androgen-receptor pathway antagonists (enzalutamide, abiraterone), novel taxanes (cabazitaxel), immunotherapy (sipuleucel-T), and targeted alpha therapy (radium-223).

A large majority of men with metastatic CRPC (90\%) will develop bone metastases, which are often initially asymptomatic. ${ }^{6,7}$ Although a small proportion of patients are de novo diagnosed with metastatic disease, most bone metastases develop in patients who have failed local treatment and progress under androgen-deprivation therapy. Bone metastases are strongly associated with increased mortality in men with metastatic CRPC, and the risk of death is even higher in men with skeletal-related events. ${ }^{8,9}$ In addition to increased mortality, bone metastases are a major cause of disability, bone pain, impaired quality of life (QoL), and excessive treatment costs. ${ }^{6,10}$ Pain is the most common symptom, occurring in $75 \%$ of symptomatic patients with metastatic $\mathrm{PC}^{7}$ whereas spinal cord compression occurs in up to $12 \%$ of patients and may be the first sign of bone metastases. ${ }^{11}$

To better understand the symptoms associated with advanced PC (aPC) and the impact of symptoms on the lives of patients and their caregivers, an international survey was commissioned by the International Prostate Cancer Coalition. The goals of the survey were to describe the disease burden, highlight barriers that prevent men from discussing symptoms, explore the patient-caregiver dynamic, and raise awareness of the importance of discussing symptoms with health care providers.

\section{Patients and Methods}

This survey (see Supplemental Figure 1 for full survey questionnaire) was conducted online and by phone by the Harris Poll in Brazil, Europe (France, Germany, Italy, the Netherlands, Spain, and the United Kingdom), Asia-Pacific region (APAC; Japan, Singapore, and Taiwan), and the United States from February 12, 2015, to October 27, 2015. The survey was provided to respondents in the following local languages: American English, British English, German, French (France and Belgium), Italian, Spanish, Dutch (Netherlands and Belgium), Japanese, Traditional Chinese (Taiwan), and Portuguese (Brazil). After the surveys were translated from the US English version to the local language by local translators, the surveys were then reviewed by in-country representatives familiar with the survey topic to ensure that the meaning of the questions would be understood in the same way across the different countries.

Survey respondents were selected from among individuals who had agreed to participate in surveys through the Harris Poll and their partners or were recruited to participate by patient advocacy organizations. Sampling methods included a convenience sample from patient advocacy organizations. Respondents were included in the survey if they lived in 1 of the 11 participating countries, were aged $\geq 18$ years, and had a diagnosis of aPC (respondents reported having PC in locations other than the prostate). A caregiver was defined as someone who had provided unpaid care to a friend or family member diagnosed with aPC. Patient care may have included providing support or assistance to a friend or family member; however, this definition did not include care provided by a health care professional or someone with formal volunteering experience. Eligible caregivers were aged $\geq 18$ years, were caring for someone with aPC, and lived in the same country in which the patient lived. Informed consent was obtained at the start of the online survey.

Demographic information was obtained from all respondents. Questions included in the survey assessed general health, concerns about personal health, symptoms, challenges faced living with aPC, and comfort level when speaking with health care providers.

The sample was based on the individuals who agreed to participate in panels or advocacy groups; therefore, it was not possible to estimate a theoretical sampling error. Because sample sizes varied between countries, the findings were adjusted to ensure that data from all countries received an equal weight in global and regional data analyses. Country-level data were unweighted. Data were analyzed using descriptive statistics, cross-tabulations, and correlations. Between-group differences were analyzed using a standard $t$ test at the $95 \%$ confidence level $(P<.05)$. Because of the small base size, comparisons versus APAC and Brazil are directional in nature and should be interpreted with caution.

\section{Results}

The study sample consisted of 927 men with aPC (weighted $\mathrm{n}=664)$ and 400 caregivers who responded to the survey and met eligibility requirements; the overall weighted $n$ value of 664 or the weighted $\mathrm{n}$ values by country, as indicated later in this article, were used to calculate the reported percentages. Overall, the mean patient age was 65.7 years, and $86 \%(\mathrm{n}=570)$ of patients had a caregiver. Patients from the United States and Europe were similar in age (mean, 67.9 and 67.8 years, respectively), as were patients from the APAC and Brazil (61.7 and 62.6 years) (Table 1).

In the total population, $84 \%$ of the men had been diagnosed with PC for longer than 12 months (Table 1). Among patients with aPC, the bone compartment was the most observed site for metastases, followed by lymph node involvement. Most patients in all regions had confirmed bone metastases (Table 1).

Most patients had caregivers, with the proportion somewhat greater in the APAC and Brazil compared with Europe and the United States (Table 1). Of the caregiver respondents in the United States, 63\% (60/95) were patients' spouses or partners compared with 49\% (179/362) in Europe and 43\% (17/40) in Brazil. In contrast, caregivers in the APAC were primarily patients' offspring $(126 / 181,70 \%)$. Most caregivers were women $(n=520$, $78 \%$ ) with a mean age of 52 years. Differences in employment status were apparent between patients and caregivers. More patients were retired compared with caregivers $(n=325,49 \%$ vs. $\mathrm{n}=160,24 \%$ ), with more than twice as many caregivers working full- or part-time $(\mathrm{n}=199,30 \%)$ compared with patients $(\mathrm{n}=$ $86,13 \%)$. Patients were accompanied by caregivers to $70 \%$ of their physician visits on average, and $50 \%(\mathrm{n}=330)$ of patients relied on a spouse or caregiver to ask the most important questions about their PC issues.

Nearly all patients reported facing challenges related to their PC, the most common of which was a decreasing ability to maintain 
Table 1 Patient Demographic and Disease Characteristics

\begin{tabular}{|c|c|c|c|c|c|}
\hline Parameter & USA $(n=410)$ & EU $(n=349)$ & APAC $(n=108)$ & Brazil $(n=60)$ & Total $(n=927)$ \\
\hline Mean age (SD), y & $67.9(10.1)$ & $67.8(8.7)$ & $61.7(7.5)$ & $62.6(12.8)$ & $65.7(9.4)$ \\
\hline Patient has a caregiver, $\%$ & 78 & 84 & 90 & 90 & 86 \\
\hline \multicolumn{6}{|l|}{$\begin{array}{l}\text { Time since prostate cancer } \\
\text { diagnosis, \% of patients }\end{array}$} \\
\hline $0-12 \mathrm{mo}$ & 6 & 11 & 26 & 23 & 16 \\
\hline$>12$ mo & 94 & 89 & 74 & 77 & 84 \\
\hline \multicolumn{6}{|l|}{$\begin{array}{l}\text { Location of observed } \\
\text { metastases, } \% \text { of patients }\end{array}$} \\
\hline Bone & 53 & 72 & 53 & 53 & 63 \\
\hline Lymph nodes & 40 & 29 & 38 & 2 & 30 \\
\hline Liver & 3 & 6 & 3 & 40 & 8 \\
\hline Lung & 4 & 7 & 2 & 17 & 6 \\
\hline Other & 16 & 11 & 19 & 13 & 14 \\
\hline Not sure & 8 & 5 & 1 & 2 & 4 \\
\hline
\end{tabular}

Abbreviations: APAC $=$ Asia-Pacific region; EU $=$ European Union; USA $=$ United States of America.

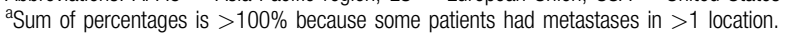

their lifestyle $(\mathrm{n}=359,54 \%)$. Caregivers most commonly reported pain management $(\mathrm{n}=394,59 \%)$ and the emotional impact on the patients' family ( $\mathrm{n}=390,59 \%)$ as the most prominent challenges faced by the patient (Figure 1).

The most commonly reported symptoms were fatigue $(\mathrm{n}=483$; $73 \%)$, urinary symptoms $(\mathrm{n}=420 ; 63 \%)$, sexual function symptoms $(\mathrm{n}=408 ; 62 \%)$, and bone pain $(\mathrm{n}=344 ; 52 \%)$. Regional differences in symptom reporting were identified (Figure 2). The symptoms most reported by region were sexual function by patients from the United States, fatigue by patients from Europe, urinary symptoms by patients from the APAC, and weight loss by patients from Brazil. Spain had the highest proportion of patients with symptoms of depression/anxiety $(n=83,86 \%)$, confusion $(n=68$, $71 \%)$, and difficulty sleeping $(\mathrm{n}=76,79 \%)$. Bone pain was reported by significantly fewer patients in the United States $(\mathrm{n}=119,29 \%)$ than in Europe $(\mathrm{n}=200,55 \% ; P<.05)$ or the APAC $(\mathrm{n}=92,51 \% ; P<.05)$ (Figure 2). Of 568 patients with bone metastases (weighted $n=421$ ), the most frequently reported symptoms were fatigue $(\mathrm{n}=367,87 \%)$; pain in specific areas, such as the back, pelvis, and hips ( $\mathrm{n}=349,83 \%)$; and generalized body pain $(\mathrm{n}=303,72 \%)$. Spain had the highest proportion of patients with bone fractures or broken bones (unweighted $n=62,76 \%$ ). Most patients with bone metastases $(n=309,73 \%)$ noticed pain before receiving a diagnosis of metastatic PC ( $\mathrm{n}=167,40 \%$ had pain for $\geq 7$ months; $\mathrm{n}=142,34 \%$ for $<7$ months). The percentage of patients who had pain for $\geq 7$ months before receiving a diagnosis of metastatic PC varied widely by country (range: 3/29, $10 \%$ in Japan to $55 / 82,67 \%$ in Spain).

In $71 \%$ of patients $(470 / 664)$, managing pain was identified as essential for effective cancer management. Men in the United States (365/410, 89\%) were more likely to strongly agree with feeling comfortable discussing their symptoms and pain with their physician compared with men in Europe $(221 / 362,61 \%)$ and the APAC $(98 / 181,54 \%)$. However, $39 \%(261 / 664)$ of patients agreed that it was difficult to talk about the amount of pain they were experiencing. Among patients who told their physicians about their pain
( $\mathrm{n}=320)$, more patients from the United States waited $\geq 1$ month to tell their physician compared with patients in Europe (Figure 3). More men in Europe (208/362, 57\%), the APAC (117/181, 65\%), and Brazil $(37 / 60,62 \%)$ than men in the United States $(146 / 410$, $36 \%)$ agreed that if that they acknowledged more pain, they would fear that their cancer is progressing. Several misconceptions about cancer-related pain were identified. Many patients with aPC were uncertain if their pain was cancer related (Figure 4). Regional differences also were identified. For example, patients in the United States were less likely than patients in Europe or the APAC to understand the relationship between their pain and aPC. Of note, $55 \%(\mathrm{n}=368)$ of patients felt they had to live with daily pain, and $45 \%(n=301)$ sometimes ignored pain.

When asked to rate the severity of pain experienced over the past week on a scale from 0 (no pain) to 10 (worst imaginable pain), caregivers rated pain severity as higher for the men they cared for than did the patients, on average (mean pain scores, 5.4 vs. 4.2, respectively). Caregivers also estimated that $66 \%(n=435)$ of the men they cared for had intermittent or constant bone pain compared with 53\% $(\mathrm{n}=351)$ of patients who rated their pain as intermittent or constant. Significantly more caregivers than patients agreed with the statement that pain limited the patients' activities ( $\mathrm{n}=479,72 \%$ vs. $\mathrm{n}=359,54 \%$, respectively; $P<.0001$ ). Patients who had a caregiver were more likely than those without a caregiver to state that pain was discussed at every health care visit (45\% vs. $32 \%, P<.05$ ).

Regional differences in the effect of pain on daily living and emotional health were observed. Compared with other countries or regions, patients in the United States were less likely to see pain as limiting their activities or as a barrier to living their lives (Figure 5). Most patients stated they would be motivated to report pain to their physician if it helped increase their QoL $(n=433$, $65 \%)$ or longevity ( $\mathrm{n}=381,57 \%)$, kept cancer from worsening $(\mathrm{n}=359,54 \%)$, or decreased cancer-related pain $(\mathrm{n}=354,53 \%)$. The use of prescription and over-the-counter (OTC) medications for pain management was common in this population. Overall, 


\section{Advanced Prostate Cancer Global Survey}

\section{Figure 1 Challenges Faced by Patients With Advanced Prostate Cancer and Their Caregivers. ${ }^{a} P<.05$}

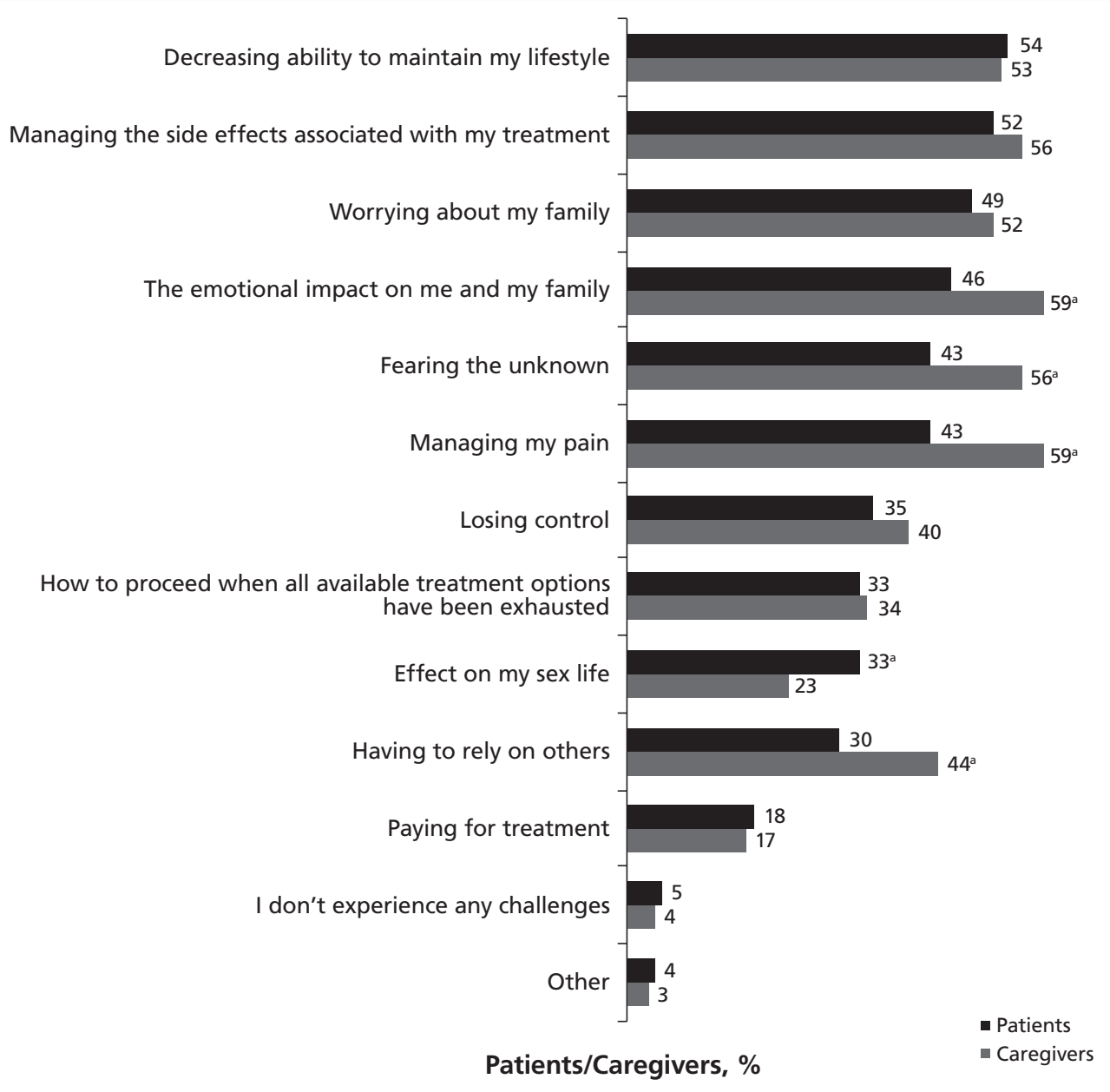

$52 \%(\mathrm{n}=348)$ of patients used prescription analgesics, and $31 \%$ ( $\mathrm{n}=209)$ used OTC pain relief medications. Patients in the United States were less likely to report using prescription analgesics $(102 / 410,25 \%)$ than patients in Europe $(179 / 362,49 \%$; $P<.05)$, the APAC $(106 / 181,59 \% ; P<.05)$, or Brazil $(48 / 60$, $80 \% ; P<.05)$, and were more likely to report using OTC analgesics $(233 / 410,57 \% ; P<.05)$ than patients in Europe $(134 /$ $362,37 \%)$, the APAC $(31 / 181,17 \%)$, or Brazil $(10 / 60,17 \%$; $P<.05)$. Of the 375 patients who used OTC analgesics, $53 \%$ ( $\mathrm{n}=110 / 209)$ used them at least several times a week and $32 \%$ ( $\mathrm{n}=66 / 209$ ) did so at least once daily.

Overall, $52 \%(\mathrm{n}=348)$ of patients were treated by oncologists and $28 \%(\mathrm{n}=188)$ by urologists. Significantly more patients in the United States (290/410, 71\%) and Brazil (53/60, 88\%) were treated by oncologists than in Europe $(201 / 362,56 \% ; P<.05)$ or the APAC $(51 / 181,28 \% ; P<.05)$. More patients in the United States $(393 / 410,96 \%)$ and the APAC $(173 / 181,96 \%)$ compared with Europe $(304 / 362,84 \%)$ and Brazil $(34 / 60,57 \%)$ stated their physician involved them in treatment decisions $(P<.05)$. Most patients $(\mathrm{n}=586,88 \%)$ reported that physicians were most likely to ask them how they were feeling (eg, including inquiries about pain and fatigue), whereas patients reported that nurses $(n=228$, $34 \%)$, physician assistants $(\mathrm{n}=145,22 \%)$, or other staff members $(\mathrm{n}=44,7 \%)$ did so less often. European and Brazilian patients were significantly more likely than their US counterparts to report that physicians ask how they were feeling (327/362, 90\% and 57/ $60,95 \%$ vs. $333 / 410,81 \% ; P<.05)$. However, patients in the United States $(226 / 410,55 \%$ and $137 / 410,33 \%$, respectively) and the APAC $(76 / 181,42 \%$ and $78 / 181,43 \%)$ were significantly more likely to report nurses and physician assistants inquire about how patients were feeling than those in Europe (86/362, 24\% and 37/ $362,10 \% ; P<.05)$. In Brazil, 55\% (33/60) of patients reported the same for nurses (which was significantly higher vs. Europe), and $15 \%(9 / 60)$ for physician assistants.

\section{Discussion}

This study of men with aPC and caregivers for patients with aPC is the largest symptom survey in this population to date and showed that the most frequently reported symptoms were fatigue, urinary symptoms, sexual function, and bone pain. Many patients ignore 


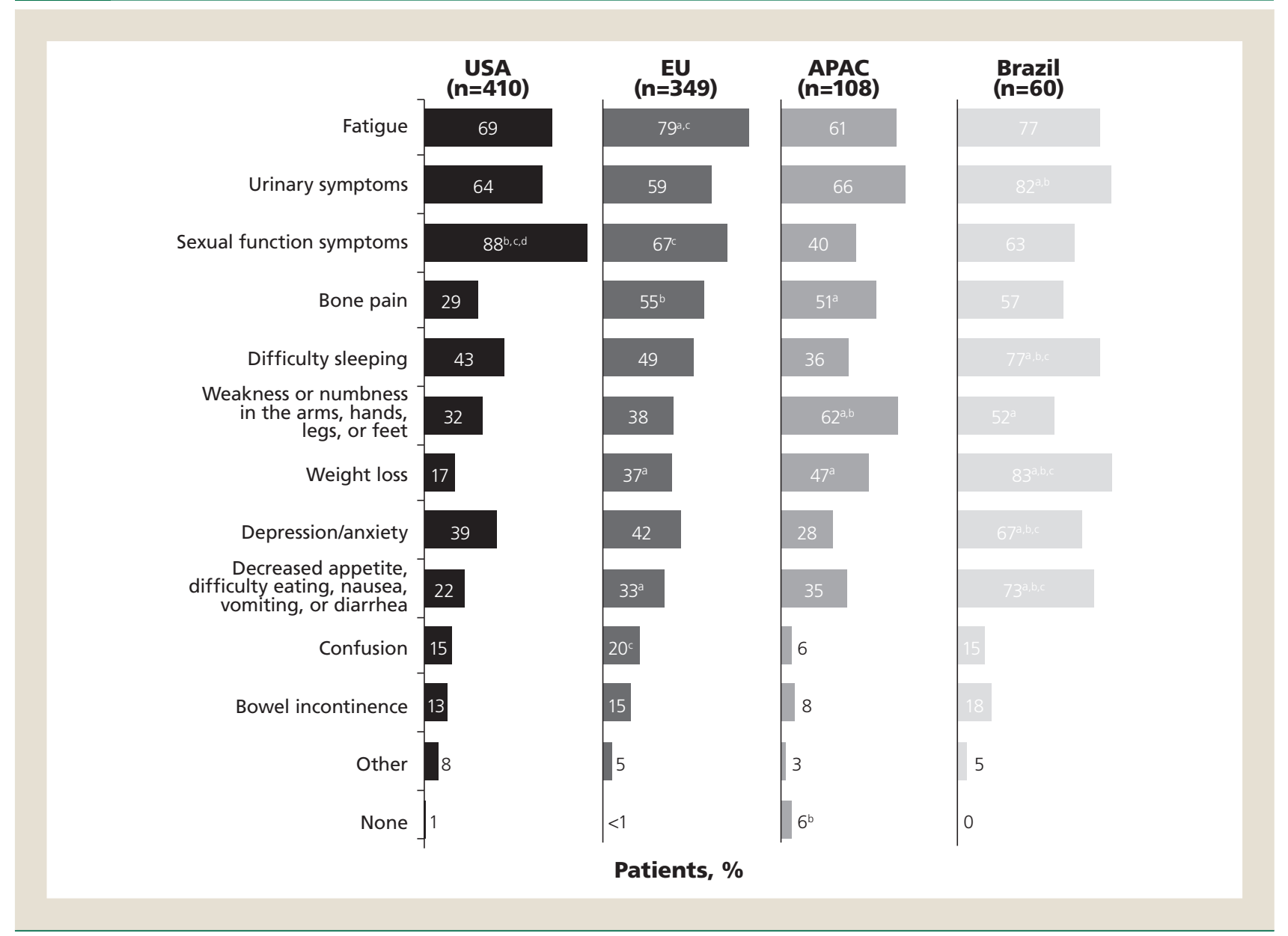

Abbreviations: APAC $=$ Asia-Pacific region; EU $=$ Europe; USA $=$ United States of America. ${ }^{\text {a }} P<.05$ Versus the USA; ${ }^{\text {b }} P<.05$ Versus EU; ${ }^{c} P<.05$ Versus the APAC; ${ }^{\mathrm{d}} P<.05$ Versus Brazil (Because of the Small Base Size for Brazil, Results Are Directional in Nature and Should be Viewed With Caution).

pain and do not bring it to the attention of their physician, possibly delaying the diagnosis of aPC or a proper course of treatment. Patients oftentimes have difficulty talking about their pain, believing that such conversations may make them appear to be weak. More than half of patients surveyed believe that daily pain or discomfort is something they need to endure and admit that they do not always know if their pain is related to cancer or to something else. Half of patients admitted that they rely on their caregivers to ask the most important questions about their PC; thus, the absence of a caregiver during an office visit represents a potential missed opportunity for relevant discussions with the physician. More than half of the men surveyed agreed that they would be more likely to discuss their symptoms if doing so increased their QoL, helped prolong their life, halted the development of metastatic disease, or increased their physical activity level. However, regional differences suggested that compared with men from the United States, those from Europe and APAC were not as comfortable discussing their physical well-being; additionally, men from Europe and APAC were more likely than men from the United States to fear that acknowledging pain means that their cancer is progressing.

This survey demonstrated that symptoms of aPC are recognized by patients and caregivers with varying degrees and influenced by global regional differences. Overall, patients with aPC noted symptoms inclusive of fatigue, lack of energy, pain (especially persistent pain requiring daily use of analgesics), weight loss, anxiety, leg weakness, loss of bladder or bowel control, and impaired interpersonal relationships. ${ }^{5,12}$

Unfortunately, many of these symptoms are relatively nonspecific (eg, fatigue, pain) and may be attributed to the everyday aches and pains associated with aging. ${ }^{13}$ However, because the presence of symptoms or changes in their frequency or severity may indicate disease progression, failure to address them in a timely manner may affect optimal diagnosis and treatment discussions. ${ }^{14}$ Effective communication between patients or caregivers and health care providers about early symptom reporting should lead to effective disease management earlier in the course of the disease.

The assessment of symptoms experienced by patients with cancer and their relation to outcomes and QoL have been the subject of several recent studies. ${ }^{15-18}$ A steering committee from the National Cancer Institute identified a core set of 12 symptoms that could be monitored in cancer treatment trials to improve cross-study comparisons of symptomatic effects. The core set of symptoms included anorexia, anxiety, cognitive problems, constipation, depression, diarrhea, dyspnea, fatigue, insomnia, nausea, pain, and sensory 


\section{Advanced Prostate Cancer Global Survey}

\section{Figure 3 Duration of Time Patients Waited to Report Pain to Their Physician}

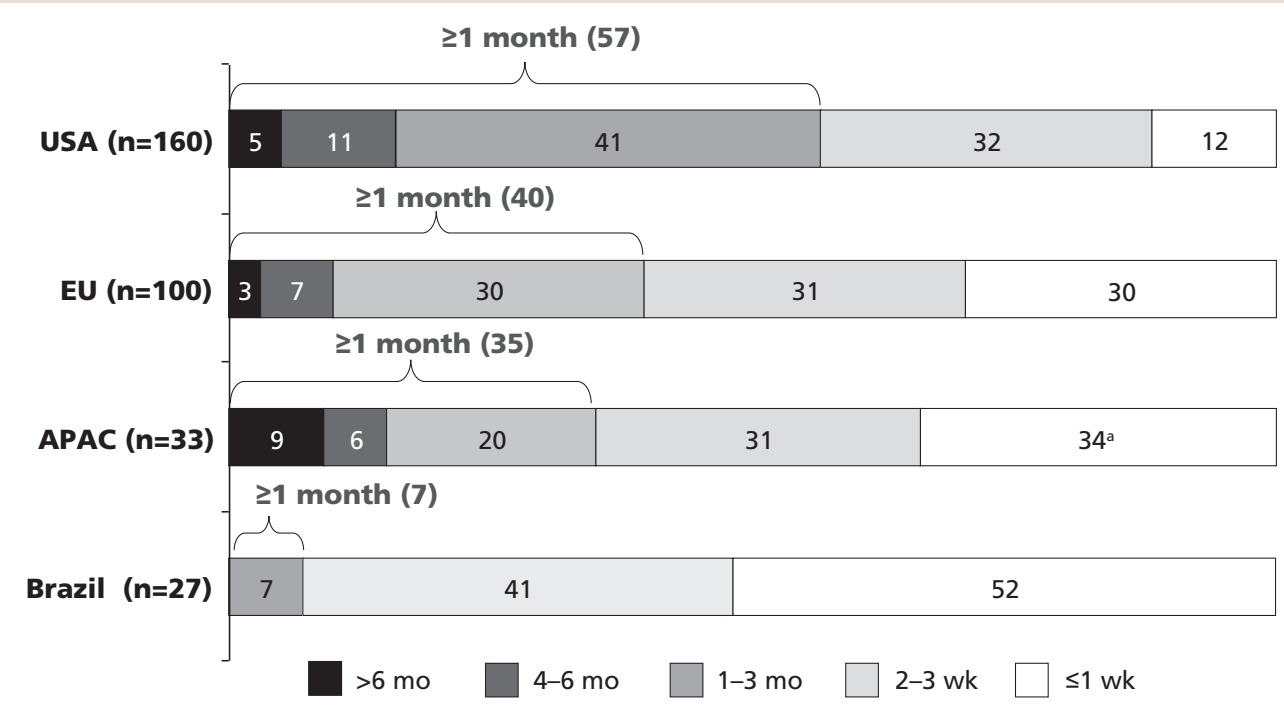

Patients Reporting Pain, \%

Abbreviations: $\mathrm{APAC}=$ Asia-Pacific region; EU $=$ Europe; USA $=$ United States of America. ${ }^{\text {a }} P<.05$ Versus the USA.

neuropathy. ${ }^{15}$ Studies specific to PC symptoms have also been conducted. ${ }^{16-18}$ Active surveillance in men with low-risk PC identified the lack of a partner, mental health issues, lack of input from physicians other than the primary physician, and fewer core biopsy samples taken at diagnosis as factors correlated with poor QoL. ${ }^{16}$ The validity of the MD Anderson Symptom Inventory (MDASI), an instrument designed to assess the relationship between cancerand treatment-related symptoms and functioning, was examined

\section{Figure 4 Patient Uncertainty About the Relationship of Pain and Cancer}

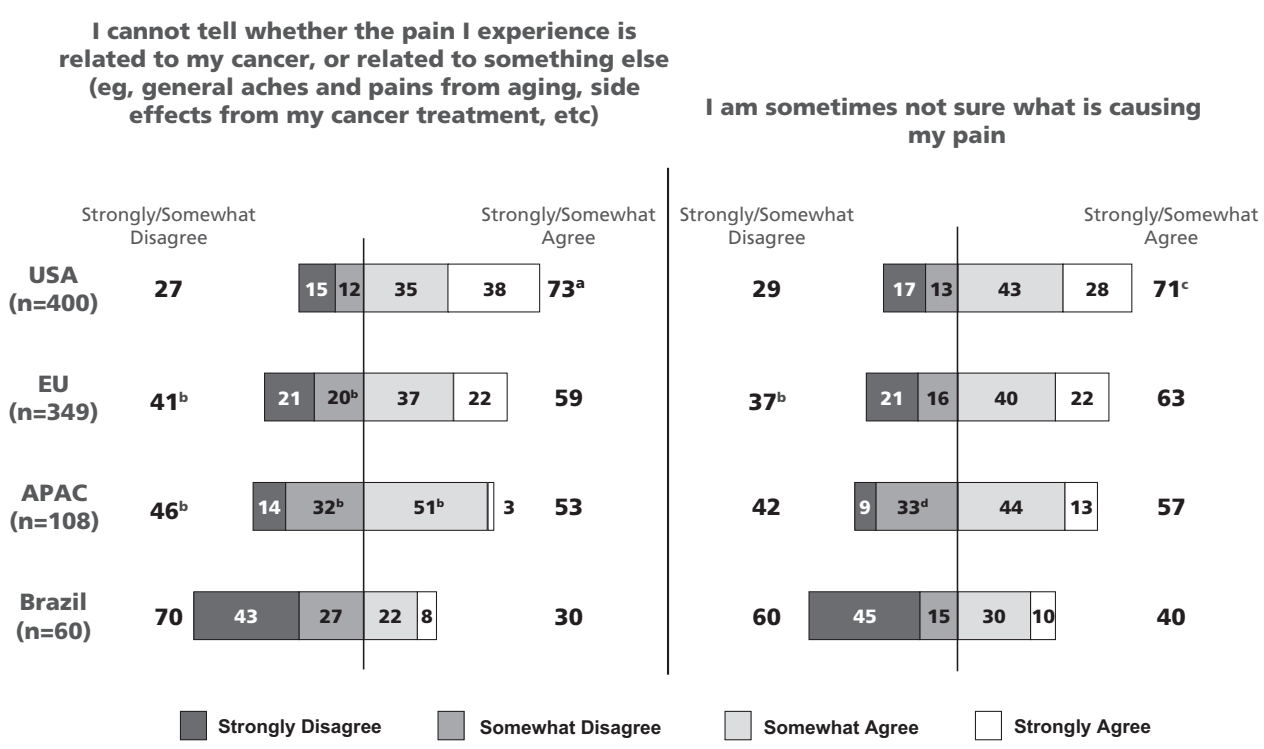

Patients, \%

Abbreviations: APAC $=$ Asia-Pacific region; EU $=$ Europe; USA $=$ United States of America. ${ }^{a} P<.05$ Versus EU and the APAC; ${ }^{b} P<.05$ Versus the USA; ${ }^{\mathrm{c}} P<.05$ Versus EU; ${ }^{\mathrm{d}} P<.05$ Versus the USA and EU. 


\section{My Pain Often Limits My Activities, \%}

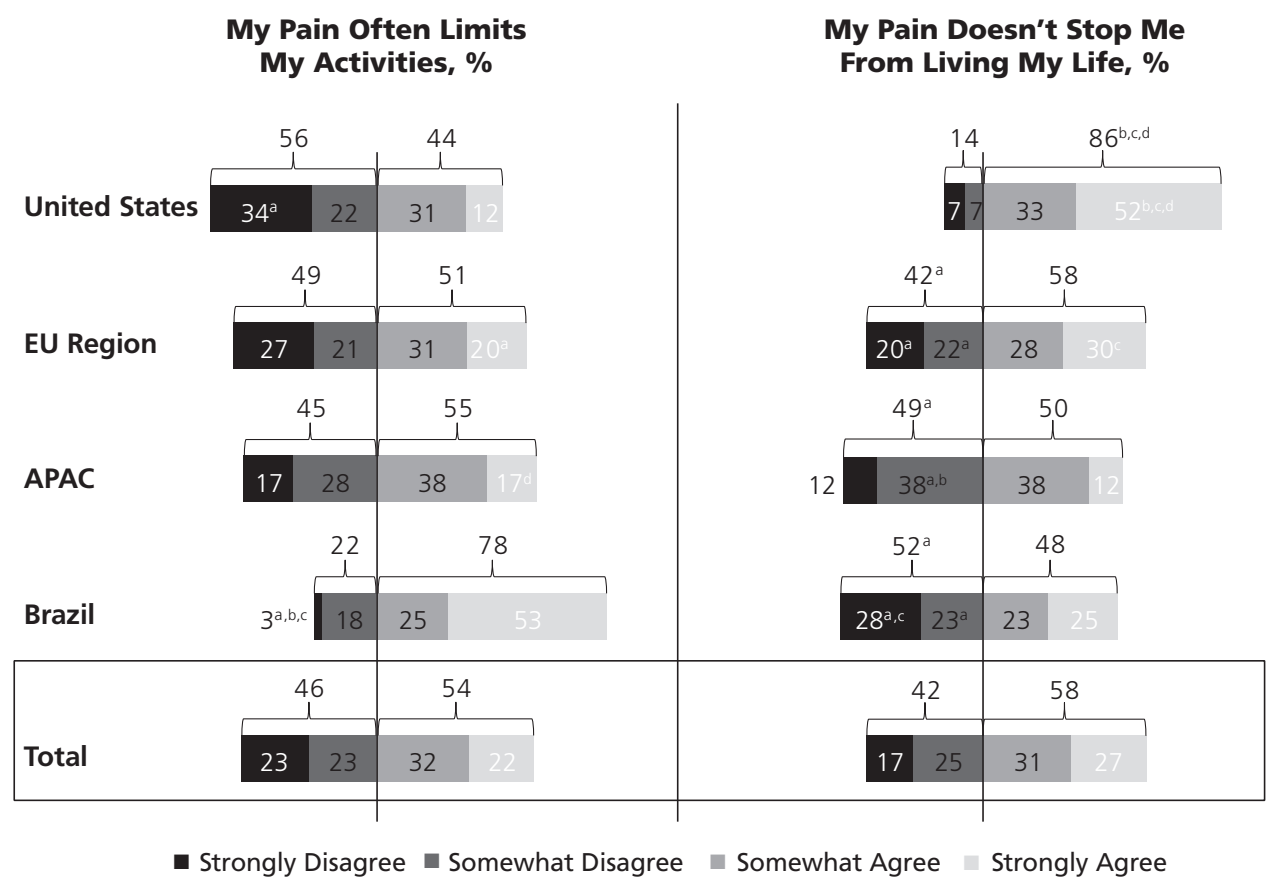

\section{My Pain Doesn't Stop Me From Living My Life, \%}

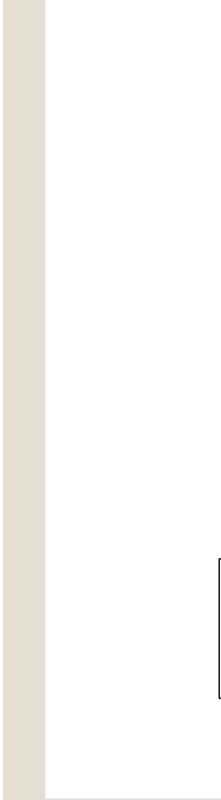

Abbreviations: APAC $=$ Asia-Pacific region; EU $=$ Europe; USA $=$ United States of America. ${ }^{a} P<.05$ Versus the USA; ${ }^{b} P<.05$ Versus EU; ${ }^{c} P<.05$ Versus the APAC; ${ }^{d} P<.05$ versus Brazil (Because of the Small Base Size for Brazil, Results Are Directional in Nature and Should be Viewed With Caution).

specifically in patients with PC. ${ }^{17}$ Evaluation of 320 patients demonstrated that the MDASI was highly sensitive in detecting disease progression and treatment response, as well as QoL based on changes in symptoms in this population. ${ }^{17}$ Physician-patient communication and shared decision making could benefit from the availability of instruments such as the MDASI. However, the quality of communication between patients and health care providers remains an area for improvement. Findings from a recent survey administered by the National Cancer Institute demonstrated few conversations between patients and physicians about PC screening and treatment options and, by extension, limited opportunity for shared decision making. ${ }^{18}$

Regional differences in patients' experiences with metastatic cancer have been reported previously. ${ }^{19}$ Results from a large global survey found that patients with advanced metastatic breast cancer in the United States were more likely to report feelings of isolation, that others misunderstand their cancer experience, and diminishing support from family and friends compared with patients from other countries. $^{19}$

Participation in surveys may improve patient outcomes, as demonstrated by a trial of symptom monitoring in 766 patients undergoing chemotherapy. ${ }^{20}$ Patients with advanced solid tumors (metastatic breast, genitourinary, gynecologic, or lung) who were randomized to self-report symptoms using a Web-based survey achieved significant benefits compared with patients randomized to usual care in terms of fewer reductions in health-related QoL scores (38\% vs. $53 \% ; P<.001)$ and fewer emergency room visits $(34 \%$ vs. $41 \% ; P=.02) .{ }^{20}$ Moreover, after a median follow-up of 7 years, median overall survival for patients self-reporting symptoms was 5 months longer than those receiving usual care (31.2 vs. 26.0 months, $P=.03)^{21}$

Online educational tools are available to encourage communication between patients or caregivers and health care professionals. The "Men Who Speak Up" Web site (https://www. menwhospeakup.com/index.php) is a resource for patients designed to increase awareness about symptoms and encourage men to seek medical help if they notice symptoms associated with PC. These materials encourage men to seek medical help if they are experiencing difficulties performing regular activities, taking more pain relievers than normal, or having aches or pains that cannot be attributed to a specific cause. Additional materials include a patient symptom tracker for patients to provide detailed information on mobility, usual activities, mood, fatigue, sleep, QoL, and pain that can be used by their physician to evaluate symptoms. The Managing Advanced Cancer Pain Together (MACPT) Web site (http://www. macpt.eu/) is another resource that offers guidance on the management of cancer pain. ${ }^{22}$ The MACPT comprises a multidisciplinary group of cancer pain management specialists who have drawn on their expertise and current best practice guidelines to offer guidance on the management of pain in the advanced cancer setting. Materials on the MACPT Web site are aimed toward training health care providers, but they can be used by patients and caregivers as a tool to help initiate discussions about cancer pain. ${ }^{22}$ The CancerCare Web site (http://www.cancercare.org/tagged/doctor- 


\section{Advanced Prostate Cancer Global Survey}

patient_communication) provides information and resources about cancer for patients and their families. ${ }^{23}$ Information consists of counseling services from oncology social workers, educational materials (eg, podcasts, workshops, publications), financial assistance information, and experts answering frequently asked questions. ${ }^{23}$

We recognize that the cross-sectional nature of our survey prevented assessment of changes in attitudes and relationships over time. Furthermore, the participants represented a convenience sample of patients and caregivers who agreed to particpate in panels or advocacy groups, thus possibly introducing selection bias into the results. These factors should be considered when interpreting our results. However, to our knowledge, the study reported here is the largest survey of patients with aPC to date, especially with a global population. Our results are strengthened by including patients and caregivers from around the world and asking questions about relationships with health care providers that represent a multidisciplinary team approach to patient care. We expect that future studies would include longitudinal assessments of patients with aPC to confirm our findings.

\section{Conclusions}

Disease symptoms in aPC are often underrecognized and may have marked differences between patients and caregivers, as well as significant global variations. There is an unmet need for tools that encourage effective communication between patients or caregivers and health care providers on early symptom reporting, which may lead to earlier symptom and disease management and resultant improved QoL and patient outcomes. Our data support the involvement of patients, caregivers, and allied health care professionals in shared clinical decision making.

\section{Clinical Practice Points}

- Most men with metastatic PC will develop bone metastases. Because bone metastases are often initially asymptomatic, they may evade timely identification by health care providers, resulting in delayed diagnosis and appropriate treatment.

- An international survey conducted in 927 men with aPC and 400 caregivers identified fatigue, urinary symptoms, sexual function symptoms, and bone pain as the most common symptoms reported by patients with aPC. In addition, many patients ignore pain and pain-related symptoms, do not bring it to the attention of their physician, and have difficulty talking about their pain, possibly delaying a diagnosis of aPC or a proper course of treatment.

- Effective communication among patients, caregivers, and health care providers may promote earlier symptom reporting, leading to enhanced symptom and disease management, and improved patient QoL and clinical outcomes.

\section{Acknowledgments}

The International Prostate Cancer Coalition (IPCC), with the support of Bayer Healthcare Pharmaceuticals, conducted the survey. The IPCC is led by the US advocacy organization CancerCare and includes Europa Uomo, the Spanish Group of Cancer Patients, Patient Advocates for Advanced Cancer Treatments, Prostate
Health Education Network, Prostate Cancer Research Institute, UsTOO International, and ZERO - The End of Prostate Cancer. The IPCC mission is to increase awareness of the symptoms of advancing prostate cancer and develop informational tools and resources for those who need them most.

Bayer Healthcare Pharmaceuticals funded the study. The design of study and interpretation of the data was a collaborative effort between Harris Poll, Bayer Healthcare Pharmaceuticals, their advisors, and the advocacy organizations. Harris Poll conducted the survey, and was responsible for data collection, management, and analysis.

Scientific writing support was provided by Sally Laden, MS, at C4 MedSolutions, LLC (Yardley, PA), a CHC Group Company; this support was funded by the Pharmaceuticals Division of Bayer.

\section{Disclosure}

Mr. Drudge-Coates is a consultant/advisor, speakers bureau member, and/or received research funding/honoraria/travel-related expenses from Amgen, Astellas Pharma, Bayer, and Janssen. Dr. $\mathrm{Oh}$ is a consultant/advisor and/or received honoraria from Astellas Pharma, Bayer, Janssen, and Sanofi. Dr. Tombal is a consultant/ advisor, speakers bureau member, and/or received research funding/ honoraria/travel-related expenses from Amgen, Astellas Pharma, Bayer, Ferring, Janssen Pharmaceuticals, Takeda, Steba Biotech, and Sanofi. Mr. Delacruz is a consultant/advisor for and received honoraria from Bayer HealthCare. Dr. O'Sullivan is a consultant/ advisor, speakers bureau member, and/or received research funding/ honoraria/travel-related expenses from Amgen, Astellas, Bayer, and Janssen. Dr. Shore is a consultant/advisor for Astellas, Bayer, Janssen Scientific Affairs, Dendreon, Sanofi, Takeda, Tolmar, and Ferring. Mr Tomlinson, Ms Vella Ripley, and Mr Mastris have no relationships to disclose.

\section{References}

1. International Agency for Research on Cancer/World Health Organization GLOBOCAN 2012: estimated cancer incidence, mortality and prevalence in 2012, Available at: http://globocan.iarc.fr/Pages/fact_sheets_cancer.aspx. Accessed: November 28, 2016

2. Hong JH, Kim IY. Nonmetastatic castration-resistant prostate cancer. Korean J Urol 2014; 55:153-60.

3. Hotte SJ, Saad F. Current management of castrate-resistant prostate cancer. Curr Oncol 2010; 17 (suppl 2):S72-9.

4. Kirby M, Hirst C, Crawford ED. Characterising the castration-resistant prostate cancer population: a systematic review. Int J Clin Pract 2011; 65:1180-92.

5. Cookson MS, Roth BJ, Dahm P, et al. Castration-resistant prostate cancer: AUA guideline. American Urological Association, Available at: https://www.auanet.org/ guidelines/castration-resistant-prostate-cancer. Accessed: April 18, 2017.

6. Heidenreich A, Bastian PJ, Bellmunt J, et al. EAU guidelines on prostate cancer Part II: treatment of advanced, relapsing, and castration-resistant prostate cancer. Eur Urol 2014; 65:467-79.

7. Cathomas R, Bajory Z, Bouzid M, et al. Management of bone metastases in patients with castration-resistant prostate cancer. Urol Int 2014; 92:377-86.

8. Norgaard M, Jensen AO, Jacobsen JB, et al. Skeletal related events, bone metastasis and survival of prostate cancer: a population based cohort study in Denmark (1999 to 2007). I Urol 2010; 184:162-7.

9. Sathiakumar N, Delzell E, Morrisey MA, et al. Mortality following bone metastasis and skeletal-related events among men with prostate cancer: a population-based analysis of US Medicare beneficiaries, 1999-2006. Prostate Cancer Prostatic Dis 2011; 14:177-83.

10. Coleman R, Body JJ, Aapro M, et al. Bone health in cancer patients: ESMO clinical practice guidelines. Ann Oncol 2014; 25(suppl 3):iii124-37.

11. Tazi H, Manunta A, Rodriguez A, et al. Spinal cord compression in metastatic prostate cancer. Eur Urol 2003; 44:527-32. 
12. Chen RC, Chang P, Vetter RJ, et al. Recommended patient-reported core set of symptoms to measure in prostate cancer treatment trials. J Natl Cancer Inst 2014; 106.

13. Jones MR, Ehrhardt KP, Ripoll JG, et al. Pain in the elderly. Curr Pain Headache Rep 2016; 20:23.

14. Forbes LJ, Warburton F, Richards MA, Ramirez AJ. Risk factors for delay in symptomatic presentation: a survey of cancer patients. Br J Cancer 2014; 111:581-8.

15. Reeve BB, Mitchell SA, Dueck AC, et al. Recommended patient-reported core set of symptoms to measure in adult cancer treatment trials. J Natl Cancer Inst 2014; 106. https://doi.org/10.1093/jnci/dju129.

16. Bellardita L, Rancati T, Alvisi MF, et al. Predictors of health-related quality of life and adjustment to prostate cancer during active surveillance. Eur Urol 2013; 64: 30-6.

17. Jones D, Zhao F, Fisch MJ, et al. The validity and utility of the MD Anderson Symptom Inventory in patients with prostate cancer: evidence from the Symptom Outcomes and Practice Patterns (SOAPP) data from the Eastern Cooperative Oncology Group. Clin Genitourin Cancer 2014; 12:41-9.
18. Bhuyan SS, Chandak A, Gupta N, et al. Patient-provider communication about prostate cancer screening and treatment: new evidence from the health information national trends survey. Am J Mens Health 2017; 11:134-46.

19. Miller H, Percassi D. Count us, know us, join us global survey: comparing the feelings and needs of advanced breast cancer patients in the United States with patients in Latin America, Europe, and Asia [abstr]. Cancer Res 2013; 73 (24 suppl).

20. Basch E, Deal AM, Kris MG, et al. Symptom monitoring with patient-reported outcomes during routine cancer treatment: a randomized controlled trial. J Clin Oncol 2015; 34:557-65.

21. Basch E, Deal AM, Dueck AC, et al. Overall survival results of a randomized trial assessing patient-reported outcomes for symptom monitoring during routine cancer treatment. J Clin Oncol 2017; 35(Suppl), Abstract LBA2.

22. MACPT. Managing advanced cancer pain together, Available at: http://www macpt.eu/. Accessed: December 7, 2016.

23. Cancer. Doctor-patient communication, Available at: http://www.cancercare.org/ tagged/doctor-patient_communication. Accessed: December 7, 2016. 